\title{
Comparison of amplification enzymes for Hepatitis C Virus
} quasispecies analysis Stephen J Polyak*1,2,3, Daniel G Sullivan1, Michael A Austin1, James Y Dai ${ }^{4}$, Margaret C Shuhart ${ }^{5}$, Karen L Lindsay7, Herbert L Bonkovsky ${ }^{8}$, Adrian M Di Bisceglie $^{9}$, William M Lee ${ }^{10}$, Chihiro Morishima1,6, David R Gretch ${ }^{1,5}$ and the HALT-C Trial Group

\author{
Address: ${ }^{1}$ Virology Division, Department of Laboratory Medicine, University of Washington, Seattle, WA, USA, ${ }^{2}$ Department of Microbiology, \\ University of Washington, Seattle, WA, USA, ${ }^{3}$ Department of Pathobiology, University of Washington, Seattle, WA, USA, ${ }^{4}$ Department of \\ Biostatistics, University of Washington, Seattle, WA, USA, ${ }^{5}$ Department of Medicine, University of Washington, Seattle, WA, USA, ${ }^{6}$ Department of \\ Pediatrics, University of Washington, Seattle, WA, USA, ${ }^{7}$ Division of Gastrointestinal and Liver Diseases, University of Southern California, Los \\ Angeles, CA, USA, ${ }^{8}$ Liver-Biliary-Pancreatic Center and the General Clinical Research Center, University of Connecticut Health Center, Farmington, \\ CT, USA, ${ }^{9}$ Division of Gastroenterology and Hepatology, Saint Louis University School of Medicine, St. Louis, MO, USA and ${ }^{10}$ Division of \\ Digestive and Liver Diseases, University of Texas Southwestern Medical Center, Dallas, TX, USA \\ Email: Stephen J Polyak* - polyak@u.washington.edu; Daniel G Sullivan - dsully@u.washington.edu; \\ Michael A Austin - usmarine@u.washington.edu; James Y Dai - yud@u.washington.edu; Margaret C Shuhart - mshuhart@u.washington.edu; \\ Karen L Lindsay - klindsay@usc.edu; Herbert L Bonkovsky - bonkovsky@uchc.edu; Adrian M Di Bisceglie - dibiscam@slu.edu; \\ William M Lee -William.Lee@UTSouthwestern.edu; Chihiro Morishima - chihiro@u.washington.edu; \\ David R Gretch - gretch@u.washington.edu; the HALT-C Trial Group - polyak@u.washington.edu \\ * Corresponding author
}

Published: 22 April 2005

Virology Journal 2005, 2:41 doi:10.1186/1743-422X-2-41

This article is available from: http://www.virologyj.com/content/2/I/4I

(C) 2005 Polyak et al; licensee BioMed Central Ltd.

This is an Open Access article distributed under the terms of the Creative Commons Attribution License (http://creativecommons.org/licenses/by/2.0), which permits unrestricted use, distribution, and reproduction in any medium, provided the original work is properly cited.

\begin{abstract}
Background: Hepatitis $\mathrm{C}$ virus (HCV) circulates as quasispecies (QS), whose evolution is associated with pathogenesis. Previous studies have suggested that the use of thermostable polymerases without proofreading function may contribute to inaccurate assessment of HCV QS. In this report, we compared non-proofreading (Taq) with proofreading (Advantage High Fidelity2; HF-2) polymerases in the sensitivity, robustness, and HCV QS diversity and complexity in the second envelope glycoprotein gene hypervariable region I (E2-HVRI) on baseline specimens from 20 patients in the HALT-C trial and in a small cohort of $12 \mathrm{HCV} / \mathrm{HIV}$ co-infected patients. QS diversity and complexity were quantified using heteroduplex mobility assays (HMA).

Results: The sensitivities of both enzymes were comparable at $50 \mathrm{IU} / \mathrm{ml}$, although HF-2 was more robust and slightly more sensitive than Taq. Both enzymes generated QS diversity and complexity scores that were correlated $(r=0.68 ; p<0.0001$, and $r=0.47 ; p<0.01$; Spearman's rank correlation). QS diversity was similar for both Taq and HF-2 enzymes, although there was a trend for higher diversity in samples amplified by Taq $(p=0.126)$. Taq amplified samples yielded complexity scores that were significantly higher than HF-2 samples $(p=0.033)$. HALT-C patients who were HCV positive or negative following 20 weeks of pegylated IFN plus ribavirin therapy had similar QS diversity scores for Taq and HF-2 samples, and there was a trend for higher complexity
\end{abstract}


scores from Taq as compared with HF-2 samples. Among patients with HCV and HIV co-infection, HAART increased HCV QS diversity and complexity as compared with patients not receiving therapy, suggesting that immune reconstitution drives HCV QS evolution. However, diversity and complexity scores were similar for both HF-2 and Taq amplified specimens.

Conclusion: The data suggest that while Taq may overestimate HCV QS complexity, its use does not significantly affect results in cohort-based studies of HCV QS analyzed by HMA. However, the use of proofreading enzymes such as HF-2 is recommended for more accurate characterization of HCV QS in vivo.

\section{Background}

HCV exists as quasispecies (QS) in infected individuals, consisting of a predominant viral variant and related, yet genetically distinct minor variants [1]. The study of HCV QS has historically focused on the hypervariable region 1 (HVR1) of the second envelope (E2) glycoprotein gene $[2,3]$, the most variable region of the HCV genome. Early studies revealed that E2-HVR1 is a target of neutralizing antibodies [4-10]. Immune pressure is thought to be chiefly responsible for the fixation of the mutations in this region of the E2 gene.

HCV QS have been analyzed in many different patient cohorts. HVR1 QS evolution may reflect progression of liver disease [11-15]. HCV QS also reflect the outcome of acute HCV infection [16], and responses to antiviral therapy [17]. More recent studies have investigated the effect of HCV/HIV co-infection on HCV QS dynamics [18,19]. In the current study, we analyzed 20 baseline samples from the HALT-C trial and 12 HCV-HIV co-infected patient samples. The HALT-C study is a randomized multi-center clinical trial to assess the effects of long-term pegylated interferon- $\alpha$ (peg-IFN) therapy on the progression of liver fibrosis and development of decompensated liver disease in hepatitis $\mathrm{C}$ patients who are non-responders to prior pegylated IFN plus ribavirin therapy $[20,21]$.

Viral QS have been analyzed by many techniques. Cloning and sequencing is the gold standard. Electrophoretic mobility-based assays, including single strand conformation polymorphism analysis (SSCP) and heteroduplex mobility analysis (HMA) allow determination of HCV QS heterogeneity without the need for sequencing (reviewed in [22]). HMA was originally described for analyzing the sequence heterogeneity of the envelope gene of human immunodeficiency virus (HIV) $[23,24]$. HMA involves hybridization of a radioactive probe generated from a QS variant to either heterogeneous PCR reaction products derived by direct PCR amplification from clinical specimens, or to homogeneous HVR1 sequences derived from cloned QS variants (clonal frequency analysis, CFA; [25]). Hybridizations between the probe and various target sequences result in the formation of double stranded DNA molecules (heteroduplexes) that produce shifts when the hybrids are separated on non-denaturing polyacrylamide gels. The shifts are determined by comparison to a homoduplex probe control (probe hybridized to itself). The extent of the heteroduplex shift compared to the homoduplex control is proportional to the degree of sequence divergence between the two DNA molecules. We have shown an excellent correlation between genetic diversity and complexity (number of variants) of individual QS variants derived by HMA as compared with standard cloning and sequencing of the HVR1 [11-13,25,26]. Moreover, HMA can be applied to studies of HCV QS evolution, in the context of therapy, transmission, and pathogenesis $[11,12,25-29]$.

Taq polymerase is the enzyme used in most studies of HCV QS analysis. However, given that Taq lacks proofreading activity, mathematical debates have been raised to suggest that QS evolution is overestimated by Taq induced mutations [30]. Indeed, in one report, use of Taq increased the proportion of minor QS variants [31], and we have found that, in general, QS diversity is lower if proof-reading enzymes are used instead of Taq [32]. But the question arises as to whether Taq induced mutations affect the outcomes/conclusions in cohort-based studies on HCV QS. Thus, in the current study, we compared Taq and HF-2 polymerases in terms of sensitivity and robustness, and in terms of evaluating HCV QS diversity and complexity as assessed by CFA of the E2-HVR1 on baseline specimens from 20 patients in the HALT-C trial and 12 HCV-HIV co-infected patients receiving or not receiving HAART.

\section{Results}

Clinical characteristics of the HALT-C and HCV-HIV coinfected patients are depicted in Tables 1 and 2. For HALT$\mathrm{C}$ patients, all patients were infected with HCV genotype 1 , with $10 / 20(50 \%)$ being genotype $1 \mathrm{a}$, and $7 / 20(35 \%)$ being genotype 1b. Subtype designations were not obtained for $2 / 20(10 \%)$ genotype 1 patients, and 1 patient was designated as type 1a or 1 b. $16 / 20(80 \%)$ patients were male. The average age of patients was 48.9 years, and average viral load was $10^{6.56} \mathrm{IU} / \mathrm{ml}\left(3.6 \times 10^{6}\right.$ $\mathrm{IU} / \mathrm{ml})$. For the $\mathrm{HCV} / \mathrm{HIV}$ co-infected patients, all patients were infected with HCV genotype 1, with 10/12 (83\%) 
Table I: Clinical and virological characteristics of the 20 HALT-C patients.

\begin{tabular}{|c|c|c|c|c|c|c|c|c|}
\hline \multirow[t]{2}{*}{ Patient } & \multirow[t]{2}{*}{ Age } & \multirow[t]{2}{*}{ Gender } & \multirow[t]{2}{*}{ Genotype } & \multirow{2}{*}{$\begin{array}{c}\text { Serum HCV } \\
\text { RNA at W00 } \\
\left(\log _{10}\right)\end{array}$} & \multicolumn{2}{|c|}{ Diversity } & \multicolumn{2}{|c|}{ Complexity } \\
\hline & & & & & $\mathrm{Taq}$ & HF-2 & $\mathrm{Taq}$ & HF-2 \\
\hline I & 52 & $M$ & la & 6.55 & 0.9953 & 1.0000 & 7 & I \\
\hline 2 & 54 & $\mathrm{~F}$ & $\mathrm{Ib}$ & 6.49 & 0.9905 & 1.0000 & 5 & 1 \\
\hline 3 & 51 & $M$ & $\mathrm{la} / \mathrm{b}$ & 6.99 & 0.9958 & 1.0000 & 5 & I \\
\hline 4 & 42 & $M$ & la & 6.81 & 0.9877 & 0.9894 & 6 & 2 \\
\hline 5 & 56 & $M$ & la & 7.13 & 0.9979 & 1.0000 & 4 & I \\
\hline 6 & 42 & $M$ & 1 & 6.55 & 0.9903 & 0.9912 & 8 & 6 \\
\hline 7 & 73 & $M$ & $\mathrm{Ib}$ & 6.78 & 0.9892 & 0.9877 & 7 & 5 \\
\hline 8 & 45 & $M$ & I & 6.37 & 0.9193 & 0.9805 & 7 & 6 \\
\hline 9 & 53 & $M$ & la & 7.06 & 0.9954 & 1.0000 & 2 & I \\
\hline 10 & 47 & $M$ & $\mathrm{Ib}$ & 6.35 & 0.9845 & 0.9994 & 4 & 3 \\
\hline 11 & 19 & $M$ & $\mathrm{Ib}$ & 5.72 & 0.9964 & 0.9994 & 2 & 2 \\
\hline 12 & 49 & $M$ & la & 7.06 & 0.9979 & 0.9986 & 3 & 3 \\
\hline 13 & 42 & $\mathrm{~F}$ & $\mathrm{lb}$ & 6.26 & 0.9993 & 0.9781 & 2 & 2 \\
\hline 14 & 42 & $M$ & la & 7.30 & 0.9810 & 0.9685 & 8 & 9 \\
\hline 15 & 61 & $M$ & $\mathrm{Ib}$ & 5.85 & 0.9858 & 0.9624 & 4 & 5 \\
\hline 16 & 54 & $M$ & $\mathrm{Ib}$ & 6.93 & 0.9047 & 0.9409 & 6 & 9 \\
\hline 17 & 45 & $\mathrm{~F}$ & la & 6.72 & 0.9962 & 0.9917 & 2 & 5 \\
\hline 18 & 47 & $\mathrm{~F}$ & la & 6.14 & 0.9966 & 0.9984 & 4 & 2 \\
\hline 19 & 50 & $M$ & la & 6.37 & 0.9962 & 0.9968 & 4 & 3 \\
\hline 20 & 53 & $M$ & la & 5.81 & 0.989 & 0.9943 & 6 & 5 \\
\hline AVG & 48.85 & & & 6.56 & 0.9845 & 0.9889 & 4.8 & 3.6 \\
\hline
\end{tabular}

HCV genotypes were determined by INNO-LiPA. HCV RNA was quantified with the Roche COBAS Monitor assay, and is expressed as log 10 IU/ $\mathrm{mL}$. QS heterogeneity was assessed using the clonal frequency analysis (CFA) technique. Diversity scores represent the average heteroduplex mobility ratios (HMR) for either Taq or HF-2 enzymes. Complexity scores represent the total number of distinct gel shift variants analyzed by CFA. W00 represents the week 0 or baseline sample. AVG represents average.

Table 2: Clinical and virological characteristics of the $12 \mathrm{HCV} / \mathrm{HIV}$ co-infected patients.

\begin{tabular}{|c|c|c|c|c|c|c|c|c|}
\hline \multirow[t]{2}{*}{ Patient } & \multirow[t]{2}{*}{ Age } & \multirow[t]{2}{*}{ Gender } & \multirow[t]{2}{*}{ Genotype } & \multirow{2}{*}{$\begin{array}{l}\text { Serum HCV } \\
\text { RNA }\left(\log _{10}\right)\end{array}$} & \multicolumn{2}{|c|}{ Diversity } & \multicolumn{2}{|c|}{ Complexity } \\
\hline & & & & & Taq & HF-2 & Taq & $\mathrm{HF}-2$ \\
\hline 1 & 49 & $\mathrm{~F}$ & la & 6.37 & 0.9856 & 0.9616 & 4 & 5 \\
\hline 2 & 40 & $M$ & la & 5.96 & 0.9987 & 0.9978 & 2 & 2 \\
\hline 3 & 36 & $\mathrm{~F}$ & $\mathrm{lb}$ & 5.53 & 1.0000 & 1.0000 & 1 & 1 \\
\hline 4 & 38 & $M$ & la & 6.75 & 0.9313 & 0.9715 & 8 & 11 \\
\hline 5 & 42 & $M$ & la & 6.94 & 1.0000 & 1.0000 & 1 & 1 \\
\hline 6 & 40 & $M$ & $\mathrm{Ib}$ & 5.55 & 0.9912 & 0.9997 & 5 & 2 \\
\hline 7 & 41 & $M$ & la & 6.39 & 0.9909 & 1.0000 & 6 & 1 \\
\hline 8 & 45 & $\mathrm{~F}$ & $\mathrm{la}$ & 6.25 & 0.9856 & 0.9468 & 4 & 7 \\
\hline 9 & 47 & $M$ & la & 5.68 & 0.9945 & 0.9996 & 2 & 2 \\
\hline 10 & 41 & $M$ & la & 5.92 & 0.9575 & 0.9430 & 10 & 10 \\
\hline 11 & 61 & $\mathrm{~F}$ & la & 6.83 & 0.9389 & 0.9283 & 7 & 6 \\
\hline 12 & 51 & $M$ & la & 6.99 & 0.9890 & 0.9638 & 2 & 7 \\
\hline AVG & 44.2 & & & 6.53 & 0.9803 & 0.9760 & 4.33 & 5.0 \\
\hline
\end{tabular}

HCV genotypes were determined by INNO-LiPA, while HCV RNA was quantified with the Roche COBAS Monitor assay, and is expressed a $\log _{10} 1 \mathrm{U} / \mathrm{mL}$. QS heterogeneity was assessed using the clonal frequency analysis (CFA) technique. Diversity scores represent the average heteroduplex mobility ratios (HMR) for either Taq or HF-2 enzymes. Complexity scores represent the total number of distinct gel shift variants analyzed by CFA. AVG represents average. 


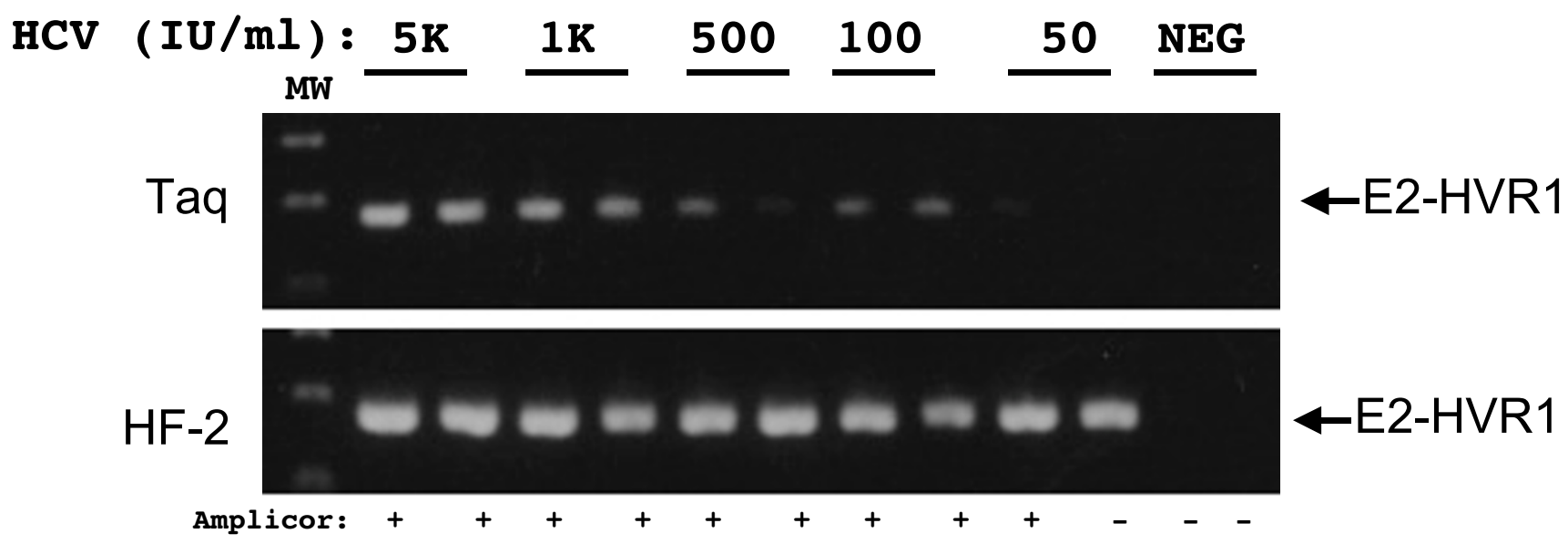

\section{Figure I}

Comparison of the sensitivity of the E2-HVRI PCR using Taq and HF-2 enzymes. RNA was extracted from duplicate serial dilutions of a WHO HCV standard and RT-PCR was performed with Taq and HF-2 enzymes. The dilutions corresponded to $50,000(5 \mathrm{~K}), \mathrm{I}, 000(\mathrm{IK}), 500,100$, and $50 \mathrm{IU} / \mathrm{ml}$, and are indicated above each lane. The position of the I76 bp E2-HVRI is indicated with arrows. MW represents the 100 base pair DNA molecular weight marker. Below each lane is the result of testing of the same dilution of the standard with the Roche COBAS Amplicor assay. The result of this test gives a positive $(+)$ or negative $(-)$ result.

being genotype $1 \mathrm{a}$, and 2/12 (17\%) being genotype $1 \mathrm{~b}$. Eight of 12 patients (67\%) were male. The average age of the co-infected patients was 44 years, and average viral load was $10^{6.53} \mathrm{IU} / \mathrm{ml}\left(3.3 \times 10^{6} \mathrm{IU} / \mathrm{ml}\right)$.

Figure 1 presents the sensitivity of the E2-HVR1 PCR using Taq versus HF-2 polymerases. Serial dilutions of the HCV international standard were run through the assay, and PCR products were visualized on agarose gels. As shown in Fig. 1, Taq produced amplification products at all dilutions, with 1 of 2 duplicate samples giving a signal at a dilution of $50 \mathrm{IU} / \mathrm{ml}$. However, the HF-2 enzyme produced more PCR product than Taq at all dilutions and both replicates were positive at $50 \mathrm{IU} / \mathrm{ml}$. Below each lane is the result of Roche COBAS Amplicor qualitative RT-PCR testing of the same serum specimens, which are scored as positive (+) or negative (-). At $50 \mathrm{IU} / \mathrm{ml}$ the Amplicor test was positive for 1 of the 2 duplicates. The data indicate that the sensitivities of the Taq and HF-2 enzymes were similar to the Amplicor assay, and the HF-2 enzyme was slightly more robust and sensitive than Taq polymerase.

The 2 enzymes produced QS diversity and complexity scores that were correlated (Linear regression analysis: Rsquared: $0.4113, \mathrm{p}<0.0001$ for diversity, and R-squared: $0.311, \mathrm{p}<0.001$ for complexity; Spearman's rank correlation test: $\mathrm{r}=0.68, \mathrm{p}<0.0001$ for diversity, and $\mathrm{r}=0.47, \mathrm{p}$ $<0.01$ for complexity). Figure 2 depicts representative clonal frequency analyses (CFA) of HALT-C baseline samples from patient 9 (figure 2A), patient 6 (figure 2B) and patient 16 (figure 2C), amplified by both Taq and HF-2 enzymes. The first lane of each gel represents the homoduplex probe control, obtained by hybridizing the radiolabeled probe to its non-labeled self. The homoduplex (designated as "HD" in the figure) serves as the reference point for all comparisons of individual clonal gel shift patterns. The second lane of each gel represents the heterogenous (ie non-clonal) PCR product, which contains all the QS variants amplified from the serum sample, and is designated as " $\mathrm{H}$ " in the figure. For each CFA, a shift control is also included, which involves the hybridization of the probe hybridized to a different HVR1 PCR product. In all cases, shift controls produced clearly identifiable shifts, indicating the hybridization reaction and electrophoresis was successful (data not shown). An internal control is also derived from a comparison of the heterogenous PCR product (" $H$ ") versus CFA gel shift patterns. If the gel shift patterns of the individual clones are representative of the heterogenous PCR product, the CFA was successful $[11,26,27]$.

As shown in Figure 2A, patient 9 had very few discernible gel shifts, and the shifts themselves were not very distinct from the homoduplex probe control. The same pattern was observed when either Taq or HF-2 was used. Indeed, HMR scores for Taq and HF-2 (0.9954 vs. 1.0000) were 


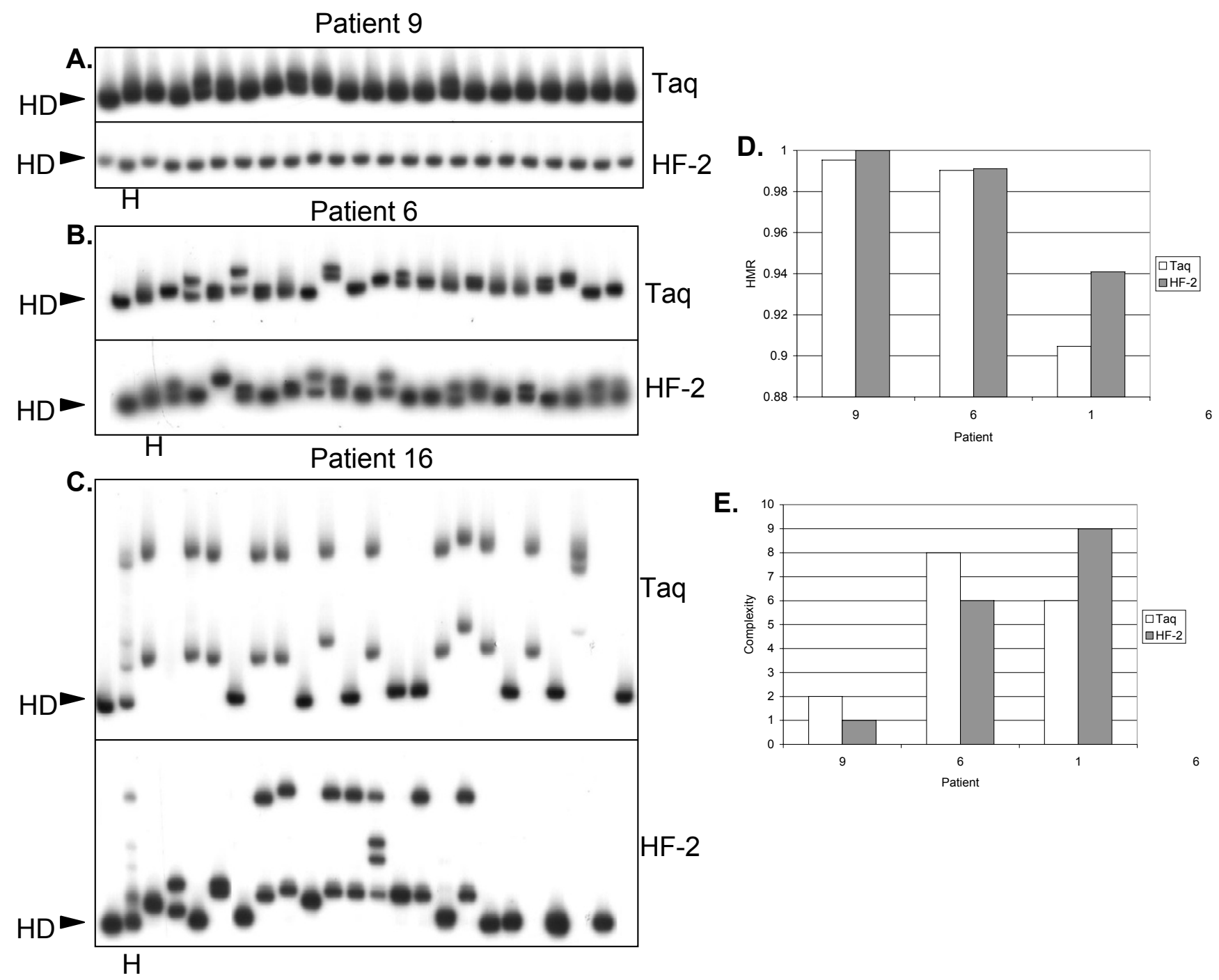

\section{Figure 2}

Representative autoradiograms of clonal frequency analyses of HALT-C patients with low (patient 9, panel A), intermediate (patient 6, panel B) and high (patient 16, panel C) QS diversity and complexity. E2-HVRI RT-PCRs were performed with Taq and HF-2 enzymes. PCR products were cloned as described in the Materials and Methods, and individual colonies were picked and re-amplified. Lane I represents the homoduplex $(\mathrm{HD})$ control and represents the probe hybridized to itself. Lane 2 represents the heteroduplex profile of the heterogenous (ie not cloned) E2-HVRI PCR product and is designated "H". Panels D and E are graphical summaries of HMR and Complexity in the 3 patients.

similar, as were the complexity scores for samples analyzed by Taq and HF-2 ( 2 vs.1 variants). The flat line nature of the CFA pattern was not due to a failure of the hybridization reaction, because the shift control (the same probe hybridized to a different HVR1 PCR product) produced a significant gel shift (data not shown). Moreover, the same pattern was observed when the heterogenous PCR product (prior to cloning) was hybridized to the probe (Figure $2 \mathrm{~A}$, lane 2 ). The results indicate that this patient had minimal QS heterogeneity. In contrast, patient 6 had clearly identifiable gel shifts when compared to the probe (Figure $2 \mathrm{~B}$ ). The same pattern was observed whether the reaction was performed with Taq or HF-2 enzyme. Again, Taq and HF-2 scores were similar both for HMR (0.9903 vs 0.9912 (Taq vs. HF-2)) and complexity ( 8 vs. 6 variants (Taq vs. HF-2)). The gel shift 

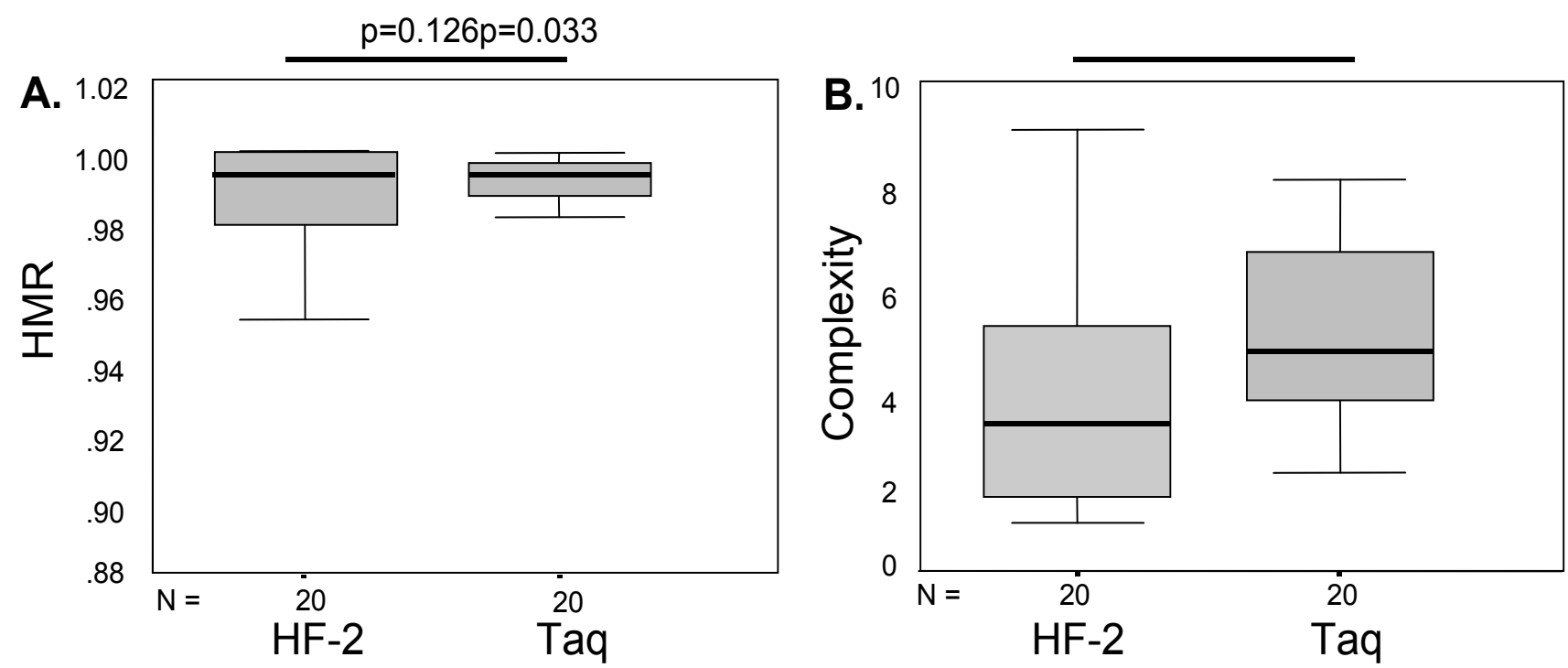

Figure 3

Comparison of quasipecies genetic diversity (assessed by HMR, Panel A) and complexity (panel B) values in samples processed with Taq or HF-2 polymerases in HALT-C baseline specimens. The box plots represent the means and ranges of the HMR and complexity scores for $400 \mathrm{HVRI}$ clones amplified by each polymerase, for a total of 800 clones $(20$ patients $\times 20$ clones/patient $\times 2$ enzymes). Error bars represent standard deviations. Significance values above each panel were derived from Wilcoxon Signed Ranks tests.

pattern observed with CFA was similar to the pattern observed when heterogenous PCR product from the same time point was hybridized to the probe (Figure $2 \mathrm{~B}$, lane $2)$. Patient 16 displayed even more marked QS heterogeneity (Figure 2C). This was quantitated both in terms of HMR (0.9047 vs. 0.9409 (Taq vs. HF-2)) and complexity ( 6 vs. 9 variants, (Taq vs. HF-2)). The bar graphs in Figures 2D and 2E summarize the diversity (HMR) and complexity data, and confirm the progressively increasing QS diversity and complexity in patients 9, 6, and 16. Note that increased QS diversity is reflected as a decrease in HMR.

Furthermore, Taq gave lower HMRs indicative of higher diversity in all 3 patients, and higher complexity scores in 2 of the 3 patients. The data suggest that Taq may overestimate HCV QS genetic diversity and complexity when analyzed by HMA.

To further examine this issue, CFA was performed for 20 HALT-C baseline specimens, and QS diversity scores and complexity scores were determined. These data are summarized in Table 1 and depicted graphically in Figure 3. Figure 3A depicts the HMR results, while Figure 3B depicts the complexity scores for the 20 HALT-C patients analyzed by both enzymes. The average HMR for Taq amplified samples was 0.9845 (range 0.9047-0.9993), while the average HMR for the HF-2 enzyme was 0.9889 (range 0.9407-1.000). Taq samples appeared somewhat more diverse than HF-2 samples. However, this trend did not reach statistical significance $(\mathrm{p}=0.126)$. Similarly, the average complexity for Taq amplified samples was 4.8 (range 2-8), while the average complexity for the HF-2 enzyme was 3.6 (range 1-9). QS complexity scores were higher in samples amplified by Taq as compared with samples amplified by HF-2 ( $\mathrm{p}=0.033)$.

Cumulatively, the data indicate that Taq overestimates HCV QS genetic diversity and complexity. However, what is not clear is whether this tendency for overestimation by Taq impacts QS scores in clinical studies.

To address this issue, we grouped the 20 HALT-C patients according to whether they were serum positive or negative for HCV RNA following 20 weeks of pegylated IFN plus ribavirin therapy. By this criterion, 6 patients were $\mathrm{HCV}$ RNA negative and 14 patients were HCV RNA positive at week 20. Figure 4 presents the HMR and complexity scores for the 2 groups of patients and demonstrates that HMR and complexity scores were similar among patients who were HCV RNA negative or positive following 20 weeks of peg-IFN plus ribavirin, regardless of the enzyme used. There was a trend for HF-2 samples generating lower complexity scores as compared to Taq samples, but the 

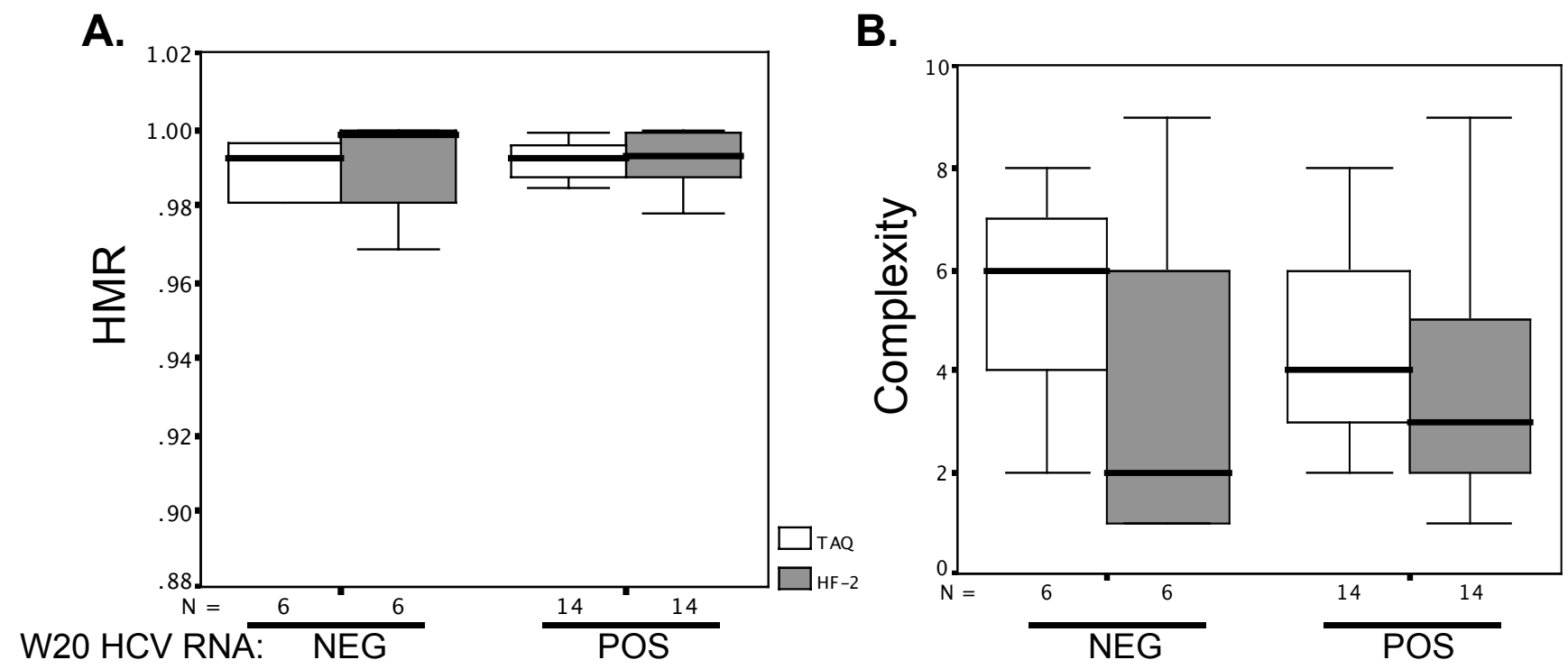

\section{Figure 4}

Comparison of quasipecies genetic diversity (assessed by HMR, Panel A) and complexity (panel B) scores generated with Taq or HF-2 polymerases, in 20 HALT-C samples who were HCV RNA negative $(N=6)$ or HCV RNA positive (N = I4) at week 20 (W20) of pegylated IFN plus ribavirin therapy. The box plots represent the means and ranges of the HMR and complexity scores for $400 \mathrm{HVRI}$ clones amplified by each polymerase, for a total of 800 clones (20 patients $\times 20$ clones/patient $\times 2$ enzymes). Error bars represent standard deviations. Wilcoxon Signed Ranks tests determined that the differences between enzymes and patient groups were not statistically significant.

difference was not significant. Note also that the lower complexity scores from HF-2 as compared with Taq processed samples among week 20 responders and nonresponders mirrored the results when all patients were considered together (Figure 3 ).

To further determine if the choice of amplification enzyme affects results in patient cohort studies, we compared QS diversity and complexity on samples from 12 $\mathrm{HCV} / \mathrm{HIV}$ co-infected patients treated or not treated with highly active anti-retroviral therapy (HAART). As shown in Figure 5, patients receiving HAART had increased QS diversity (shown as a decrease in HMR in panel A) and complexity (panel B) as compared to patients who did not receive HAART. This trend was apparent regardless of whether Taq and HF-2 were used. The increase in diversity and complexity scores upon HAART did not reach statistical significance. Moreover, HMR and complexity scores were not significantly different between Taq and HF-2 samples. In fact, HAART-samples amplified by HF-2 showed a trend for higher complexity scores (complexity $=4$ ) as compared with Taq samples (complexity =3.2). These data suggest that although Taq may overestimate QS complexity, it likely does not mask potentially important clinical associations when HCV QS are analyzed by HMA.

\section{Discussion}

In the current investigation, we found that the sensitivity of Taq and HF-2 enzymes in amplifying the E2-HVR1 were similar to the qualitative Roche COBAS Amplicor RT-PCR assay. The HF-2 enzyme generated more PCR product and was more sensitive than Taq. For HALT-C samples, QS diversity, expressed as an HMR, was similar for both Taq and HF-2 enzymes, although Taq tended to give higher diversity scores. HCV QS complexity was significantly higher in samples amplified by Taq as compared with samples amplified by HF-2. In contrast, in $\mathrm{HCV} / \mathrm{HIV}$ co-infected samples, diversity and complexity scores were similar for both enzymes. The data from this limited cohort suggest that QS results are not significantly influenced by choice of polymerase when using the CFA method.

Our data indicate that Taq induced errors provide inflated estimates of HCV QS diversity and complexity. The data are in accord with previous mathematical models of HCV QS mutations [30], and a recent study that demonstrated that Taq induced errors can generate minor QS variants [31]. However, our results showed only a trend for increased HMR for Taq amplified HALT-C samples as well as for HMR and complexity scores for HCV/HIV coinfected samples. Based on the current results, it would 

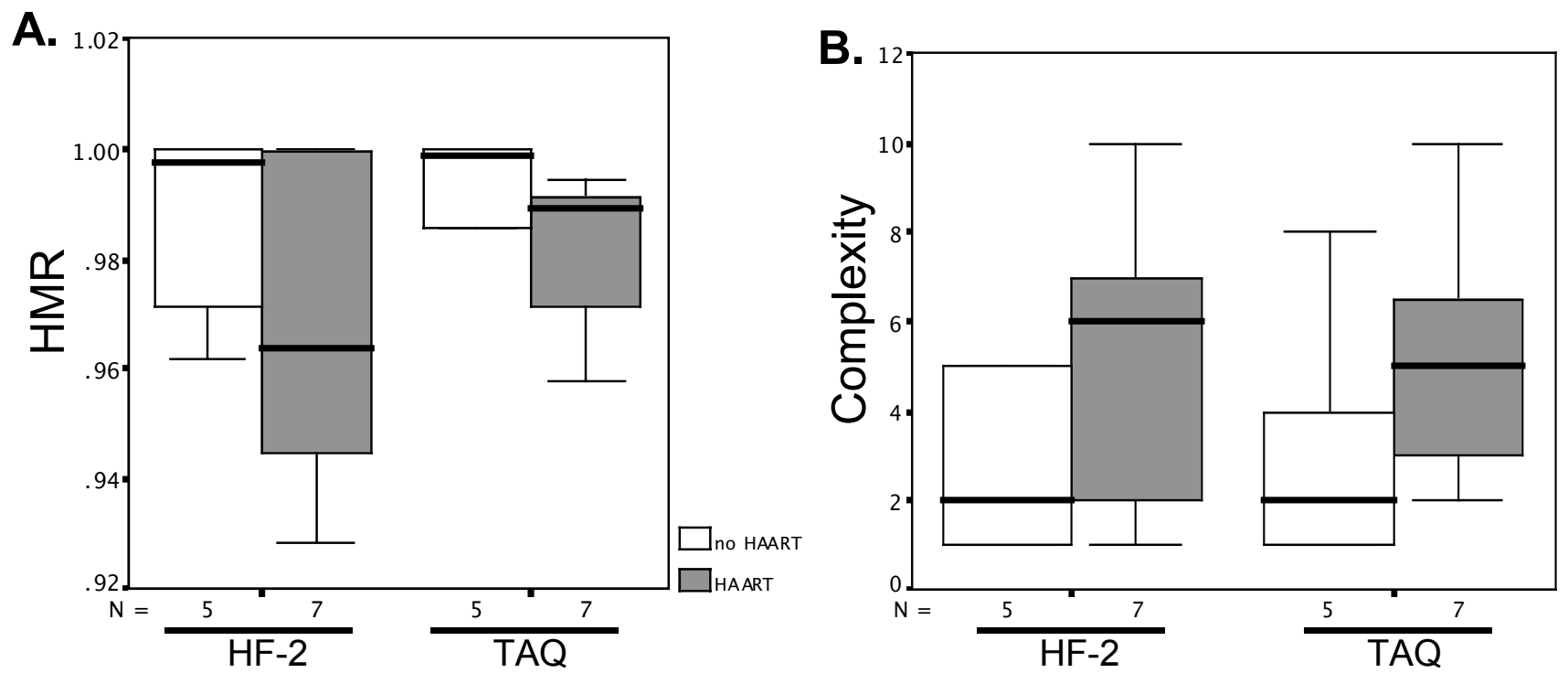

Figure 5

Comparison of quasipecies genetic diversity (assessed by HMR, Panel A) and complexity (panel B) values processed with Taq or HF-2 polymerases, in $12 \mathrm{HCV} / \mathrm{HIV}$ co-infected samples treated $(\mathrm{N}=7)$ or not treated $(\mathrm{N}=5)$ with HAART. The box plots represent the means and ranges of the HMR and complexity scores for $240 \mathrm{HVRI}$ clones amplified by each polymerase, for a total of 480 clones ( 12 patients $\times 20$ clones/patient $\times 2$ enzymes). Error bars represent standard deviations. Wilcoxon Signed Ranks tests determined that all differences were not statistically significant.

seem that Taq and proof-reading enzymes are acceptable for HCV QS analyzed by CFA. However, further studies on larger patient cohorts need to be performed.

Genetic evolution in the E2-HVR1 is believed to reflect selective forces imposed on this domain by neutralizing antibodies [4-10]. It is also possible that cell mediated immune responses may impart selective pressures on HVR1. In the face of immune pressure, the plasticity of the HVR1 may allow the virus to persist. However, recent studies suggest that the HVR1, although it is the most variable region in the HCV genome, has certain constraints in its structure. It is intriguing that key basic residues are highly conserved, which maintains the chemicophysical properties and conformation of the HVR1 [33]. Because HVR1 is an exposed domain on the E2 protein, these data suggest that the positively charged HVR1 is involved in interactions with negatively charged molecules such as lipids, proteins, or glycosaminoglycans (GAGs). As such, the HVR1 may interact with GAGs facilitating host cell recognition and attachment [33]. In this regard, it has recently been shown that high pretreatment HCV QS diversity and complexity at baseline are associated with non-response to pegylated IFN ribavirin in HALT-C patients [34].
HAART therapy appeared to increase HCV QS diversity and complexity, regardless of the enzyme used, but this did not reach statistical signficance in this small cohort. These data are consistent with recent reports that suggest that HAART-induced immune reconstitution drives HCV QS evolution [18,19]. Additional prospective trials on larger patient cohorts are required to further examine the relationships between immune pressure, HCV QS evolution, and liver disease progression in patients co-infected with HIV and HCV.

\section{Materials and methods Patients}

Twenty patients who met entry criteria for the HALT-C trial were included in the current study. Serum samples from baseline (week 0; (W00)), prior to the start of IFN therapy, were analyzed. Written, informed consent was provided by all patients, following institutional and trial specified IRB regulations. The design and conduct of the HALT-C trial have been described [21]. Briefly, in the initial or lead-in course of therapy, all patients are treated with pegylated interferon (Pegasys, Roche) plus ribavirin for a period of 24 weeks, with virologic assessment at 20 weeks to assess whether or not they are virological responders. Patients who are responders at week 20 continue treatment and receive a full course of 48 weeks of 
therapy. Those who remain HCV-positive in serum at 20 weeks are randomized to receive either continued lowdose pegylated interferon (without further ribavirin) or no further treatment beyond careful observation for the ensuing 3.5 years. Immunology and virology ancillary studies including QS analysis are aimed at increasing our understanding of the complex interactions of virus and host in this debilitating and widespread disease [34].

Samples from twelve patients co-infected with HCV and HIV were also analyzed. Seven of these patients received HAART, while 5 patients did not. All 32 patients were infected with HCV of genotype 1.

\section{E2-HVRI RT-PCR Amplification and Cloning}

HCV RNA was extracted from $100 \mu \mathrm{L}$ of patient sera using HCV RNA isolation columns (Qiagen). RNA was resuspended in DEPC-treated water, and converted into CDNA using oligonucleotide primers and AMV reverse transcriptase, as described previously [26]. The same cDNA sample was then amplified using either Taq (Perkin Elmer, Wellesley, MA) or Advantage High Fidelity 2 (HF2) (Clontech; Mountain View, CA) polymerases, using a nested PCR reaction as described [26]. To provide a hot start, AmpliWax (Perkin Elmer) beads were used to separate Taq enzyme and primers, whereas the HF- 2 enzyme mixture contains an anti-Taq antibody. The primers generated the expected second round product of 176 base pairs. PCR products were excised and purified with the QiaEx purification system (Qiagen, Valencia, CA), ligated into pCR2 vector, and transformed into TOP10 cells as described [11].

\section{Sensitivity of E2-HVRI PCR Assay}

To determine the sensitivity of the E2-HVR1 PCR assay using Taq versus HF-2 polymerases, serial dilutions of an HCV World Health Organization (WHO) international standard [35] were prepared from 50,000 to 50 International Units/milliliter ( $\mathrm{IU} / \mathrm{ml})$. RNA was extracted, converted into CDNA and amplified by nested PCR as described above. PCR products were separated on agarose gels. Aliquots of WHO standards were also run through the Roche Amplicor assay for internal comparison.

\section{HCV RNA quantitation and genotyping}

HCV RNA was qualitatively measured by RT-PCR using the Roche COBAS Amplicor HCV test version 2.0 (RocheMolecular Systems, Branchburg, NJ), and quantitatively using Roche COBAS Amplicor HCV Monitor v. 2.0 (Roche Molecular Systems, Branchburg, NJ). Genotyping was performed using the INNO-LiPA HCV II Kit (Bayer Diagnostics, Emeryville, CA) All assays were performed according to manufacturer's specifications.

\section{Clonal Frequency Analysis (CFA)}

For each cloned HVR1 PCR product, 20 colonies were picked directly into tubes for re-amplification of the second round PCR product. Thus, for each patient, 20 PCR products representing 20 individual QS clones derived from the baseline serum were analyzed. PCR products were visualized on ethidium bromide-stained agarose gels, and one HVR1 PCR product was randomly selected, purified as described above, and end-labeled with ${ }^{32} \mathrm{P}$ ATP and T4 polynucleotide kinase. Unincorporated label was separated with Centrisep columns (Princeton Separations, Adelphia, NJ), and the labeled DNA probe was eluted from the column. Labeled probe was hybridized directly to each amplified PCR product for 2 hours at $55^{\circ} \mathrm{C}$ as described [11]. Hybrids were separated on $6 \%$ non-denaturing polyacrylamide MDE gels (Cambrex, Baltimore, $\mathrm{MD)}$ and visualized by autoradiography as described [11].

\section{Data Analysis}

QS complexity was determined by counting the total number of unique gel shift patterns. QS genetic diversity was determined by deriving the average heteroduplex mobility of all clones relative to the homoduplex probe control. A heteroduplex mobility ratio (HMR) was calculated by dividing the distance in millimeters $(\mathrm{mm})$ from the origin of the gel to the heteroduplex by the distance in $\mathrm{mm}$ from the origin to the homoduplex control. In cases where both strands of the heteroduplex were clearly distinguishable, the average of the distance of each strand of the heteroduplex was used to calculate heteroduplex mobility [25]. The HMRs for all variants in the population were averaged to provide the final HMR value. Non-parametric Wilcoxon Signed Ranks tests were used to compare the differences in QS complexity and diversity scores between the different enzymes. Linear regression analysis and Spearman's rank correlation tests were also used to determine the correlation of Taq and Ad-HF2 measurements of QS diversity and complexity.

\section{Acknowledgements}

This is publication number 9 from the HALT-C Trial Group. Financial support: This study was supported by the National Institute of Diabetes \& Digestive \& Kidney Diseases and the National Institute of Allergy and Infectious Diseases under contract numbers NOI DK92318, DK92319, DK9232I, DK92324, DK92325, DK92326, and DK92328, with supplemental funds from the National Cancer Institute, the National Center for Minority Health and Health Disparities and by General Clinical Research Center grants from the National Center for Research Resources, National Institutes of Health (grant numbers MOI RR00043, RR00633, RR06192). Additional funding to conduct this study was provided by Roche Laboratories, Inc.

Authors with no financial relationships to disclose are: SJP, DGS, MAA, JYD, and CM. Financial relationships of authors with Roche Laboratories/Hoffmann-La Roche, Inc., are as follows: MCS is a consultant and speaker's bureau member; KLL is a consultant and receives research support; HLB is a consultant, speaker's bureau member, and receives research support; 
AMDB is a consultant, speaker's bureau member, and receives research support; WML is a speaker's bureau member and receives research support; and DRG receives educational grant support.

The authors gratefully acknowledge the HALT-C study investigators, research staff, and participants. The members of the HALT-C Trial Group who contributed to the performance of the clinical study are: Dawn Bombard, RN; Minjun Chung; Maureen Cormier, NP-C; Nicole Crowder, LVN; Michael Doherty, MS; Rivka Elbein, RN; Donna Giansiracusa, RN, BSN; Carol B. Jones, RN; Michelle Kelley, ANP; Debra King, RN; Rachel Life, BS; Peter F. Malet, MD; Savant Mehta, MD; Susan L. Milstein, RN; Patricia Osmack; Amanda Reeck; Marisol Serrano; Rohit Shankar; Judy Thompson, $\mathrm{RN}$; and Elizabeth Wright, PhD.

\section{References}

I. Martell M, Esteban JI, Quer J, Genesca J, Weiner A, Esteban R, Guardia J, Gomez J: Hepatitis C virus (HCV) circulates as a population of different but closely related genomes: quasispecies nature of HCV genome distribution. I Virol 1992, 66(5):3225-3229.

2. Hijikata M, Kato N, Ootsuyama Y, Nakagawa M, Ohkoshi S, Shimotohno K: Hypervariable regions in the putative glycoprotein of hepatitis C virus. Biochem Biophys Res Commun I99I, I 75(I):220-228.

3. Weiner AJ, Brauer MJ, Rosenblatt J, Richman KH, Tung J, Crawford K, Bonino F, Saracco G, Choo QL, Houghton M: Variable and hypervariable domains are found in the regions of HCV corresponding to the flavivirus envelope and NSI proteins and the pestivirus envelope glycoproteins. Virology |99|, 180(2):842-848.

4. Farci P, Alter HJ, Wong DC, Miller RH, Govindarajan S, Engle R, Shapiro M, Purcell RH: Prevention of hepatitis $\mathbf{C}$ virus infection in chimpanzees after antibody-mediated in vitro neutralization. Proc Natl Acad Sci U S A 1994, 9 I (16):7792-7796.

5. Higashi Y, Kakumu S, Yoshioka K, Wakita T, Mizokami M, Ohba K, Ito $Y$, Ishikawa T, Takayanagi M, Nagai $Y$ : Dynamics of genome change in the E2/NSI region of hepatitis $C$ virus in vivo. Virology 1993, 197(2):659-668.

6. Kato N, Sekiya H, Ootsuyama Y, Nakazawa T, Hijikata M, Ohkoshi S, Shimotohno K: Humoral immune response to hypervariable region I of the putative envelope glycoprotein (gp70) of hepatitis C virus. J Virol 1993, 67(7):3923-3930.

7. Okamoto H, Kojima M, Okada S, Yoshizawa H, lizuka H, Tanaka T, Muchmore EE, Peterson DA, Ito Y, Mishiro S: Genetic drift of hepatitis $C$ virus during an 8.2-year infection in a chimpanzee: variability and stability. Virology 1992, 190(2):894-899.

8. van Doorn LJ, Capriles I, Maertens G, DeLeys R, Murray K, Kos T, Schellekens H, Quint W: Sequence evolution of the hypervariable region in the putative envelope region E2/NSI of hepatitis $C$ virus is correlated with specific humoral immune responses. J Virol 1995, 69(2):773-778.

9. Weiner AJ, Geysen HM, Christopherson C, Hall JE, Mason TJ, Saracco G, Bonino F, Crawford K, Marion CD, Crawford KA, et al.: Evidence for immune selection of hepatitis C virus (HCV) putative envelope glycoprotein variants: potential role in chronic HCV infections. Proc Natl Acad Sci U S A 1992, 89(8):3468-3472.

10. Ziebert $A$, Schreier $E$, Roggendorf M: Antibodies in human sera specific to hypervariable region I of Hepatitis $C$ virus can block viral attachment. Virology 1995, 208:653-66I.

II. Gretch DR, Polyak SJ, Wilson JJ, Carithers RL, Perkins JD, Corey L: Tracking hepatitis $C$ virus quasispecies major and minor variants in symptomatic and asymptomatic liver transplant recipients. J Virol 1996, 70(II):7622-763I.

12. Sullivan DG, Wilson J], Carithers RL, Perkins JD, Gretch DR: Multigene tracking of hepatitis $C$ virus quasispecies after liver transplantation: correlation of genetic diversification in the envelope region with asymptomatic or mild disease patterns. Journal of Virology 1998, 72(12): 10036-10043.

13. Wilson JJ, Polyak SJ, Day TD, Gretch DR: Characterization of simple and complex hepatitis $C$ virus quasispecies by heteroduplex gel shift analysis: correlation with nucleotide sequencing. J Gen Virol 1995, 76: 1763-I77I.
14. Lyra AC, Fan X, Lang DM, Yusim K, Ramrakhiani S, Brunt EM, Korber $B$, Perelson AS, Di Bisceglie AM: Evolution of hepatitis C viral quasispecies after liver transplantation. Gastroenterology 2002, | 23(5): | 485- | 493.

15. Fan X, $\mathrm{Di}$ Bisceglie AM: Diversification of hypervariable region I of hepatitis C virus after liver transplantation. J Med Virol 2003, 70(2):2/2-2|8.

16. Ray SC, Wang YM, Laeyendecker O, Ticehurst JR, Villano SA, Thomas $D L$ : Acute hepatitis $C$ virus structural gene sequences as predictors of persistent viremia: Hypervariable region I as a decoy. J Virol I999, 73(4):2938-2946.

17. Pawlotsky JM: Hepatitis $\mathbf{C}$ virus genetic variability: pathogenic and clinical implications. Clin Liver Dis 2003, 7(I):45-66.

18. Mao Q, Ray SC, Laeyendecker O, Ticehurst JR, Strathdee SA, Vlahov $D$, Thomas DL: Human immunodeficiency virus seroconversion and evolution of the hepatitis $C$ virus quasispecies. J Virol 200I, 75(7):3259-3267.

19. Babik JM, Holodniy M: Impact of highly active antiretroviral therapy and immunologic status on hepatitis $C$ virus quasispecies diversity in human immunodeficiency virus/hepatitis C virus-coinfected patients. J Virol 2003, 77(3):1940-1950.

20. Shiffman ML, Di Bisceglie AM, Lindsay KL, Morishima C, Wright EC, Everson GT, Lok AS, Morgan TR, Bonkovsky HL, Lee WM, et al: Peginterferon alfa-2a and ribavirin in patients with chronic hepatitis C who have failed prior treatment. Gastroenterology 2004, I 26(4): 1015-1023.

21. Lee WM, Dienstag JL, Lindsay KL, Lok AS, Bonkovsky HL, Shiffman ML, Everson GT, Di Bisceglie AM, Morgan TR, Ghany MG, et al.: Evolution of the HALT-C Trial: pegylated interferon as maintenance therapy for chronic hepatitis $\mathbf{C}$ in previous interferon nonresponders. Control Clin Trials 2004, 25(5):472-492.

22. Forns $X$, Bukh J: The molecular biology of hepatitis $\mathbf{C}$ virus. Genotypes and quasispecies. Clin Liver Dis 1999, 3(4):693-716. vii

23. Delwart EL, Shpaer EG, Louwagie J, McCutchan FE, Grez M, Rubsamen $\mathrm{WH}$, Mullins Jl: Genetic relationships determined by a DNA heteroduplex mobility assay: analysis of HIV-I env genes. Science 1993, 262(5 |37):|257-|26|.

24. Delwart EL, Sheppard HW, Walker BD, Goudsmit J, Mullins JI: Human immunodeficiency virus type $I$ evolution in vivo tracked by DNA heteroduplex mobility assays. J Virol 1994, 68(10):6672-6683.

25. Polyak SJ, Faulkner G, Carithers RL, Corey L, Gretch DR: Assessment of hepatitis $C$ virus quasispecies heterogeneity by gel shift analysis: correlation with response to Interferon therapy. I Infect Dis 1997, 175(5): I I0I-I I07.

26. Polyak SJ, McArdle S, Liu SL, Sullivan DG, Chung MJ, Hofgartner WT, Carithers RL, McMahon BJ, Mullins JI, Corey L, et al.: Evolution of hepatitis $C$ virus quasispecies in hypervariable region $I$ and the putative interferon sensitivity-determining region during interferon therapy and natural infection. J Virol 1998, 72(5):4288-4296

27. Gerotto M, Sullivan DC, Polyak SJ, Chemello L, Cavalletto L, Pontisso $P$, Alberti A, Gretch DR: Effect of retreatment with interferon alone or interferon plus ribavirin on hepatitis $C$ virus quasispecies diversification in nonresponder patients with chronic hepatitis C. Journal Of Virology 1999, 73(9):724I-7247.

28. Gerotto M, Dal P-F, Sullivan DG, Chemello L, Cavalletto L, Polyak SJ, Pontisso P, Gretch DR, Alberti A: Evidence for sequence selection within the non-structural 5A gene of hepatitis $C$ virus type Ib during unsuccessful treatment with interferonalpha. J Viral Hepatitis 1999, 6(5):367-372.

29. Sullivan DG, Kim SS, Wilson J], Stehman-Breen C, Gretch DR: Investigating hepatitis $C$ virus heterogeneity in a high prevalence setting using heteroduplex tracking analysis. J Virol Methods 200I, 96(I):5-16.

30. Smith DB, McAllister J, Casino C, Simmonds P: Virus 'quasispecies': Making a mountain out of a molehill? Journal Of General Virology 1997, 78:1511-1519.

31. Mullan B, Kenny-Walsh E, Collins JK, Shanahan F, Fanning LJ: Inferred hepatitis $C$ virus quasispecies diversity is influenced by choice of DNA polymerase in reverse transcriptasepolymerase chain reactions. Anal Biochem 200I, 289(2): I37-I 46.

32. Nousbaum J, Polyak SJ, Ray SC, Sullivan DG, Larson AM, Carithers RL $J r$, Gretch DR: Prospective characterization of full-length hepatitis C virus NS5A quasispecies during induction and combination antiviral therapy. J Virol 2000, 74(19):9028-9038. 
33. Penin F, Combet C, Germanidis G, Frainais PO, Deleage G, Pawlotsky $J M$ : Conservation of the conformation and positive charges of hepatitis C virus E2 envelope glycoprotein hypervariable region I points to a role in cell attachment. J Virol 200I, 75(I 2):5703-57I0.

34. Rothman AL, Morishima C, Bonkovsky HL, Polyak SJ, Ray R, Di Bisceglie AM, Lindsay KL, Malet PF, Chang M, Gretch DR, et al.: Associations among clinical, immunological, and viral quasispecies measurements in advanced chronic hepatitis C. Hepatology 2005, 4 I(3):617-625.

35. Saldanha J, Lelie N, Heath A: Establishment of the first international standard for nucleic acid amplification technology (NAT) assays for HCV RNA. WHO Collaborative Study Group. Vox Sang 1999, 76(3): I49-158.

Publish with Bio Med Central and every scientist can read your work free of charge

"BioMed Central will be the most significant development for disseminating the results of biomedical research in our lifetime. "

Sir Paul Nurse, Cancer Research UK

Your research papers will be:

- available free of charge to the entire biomedical community

- peer reviewed and published immediately upon acceptance

- cited in PubMed and archived on PubMed Central

- yours - you keep the copyright

Submit your manuscript here:

http://www.biomedcentral.com/info/publishing_adv.asp
BiolMedcentral 